\title{
The Empire of the Qara Khitai in Eurasian History. Between China and Islamic World. Cambridge, Cambridge University Press, 2005, X-xxvi + 1-279 p.
}

\section{Denise Aigle}

\section{(2) OpenEdition}

1 Journals

Édition électronique

URL : http://journals.openedition.org/abstractairanica/27682

DOI : 10.4000/abstractairanica.27682

ISSN : 1961-960X

Éditeur :

CNRS (UMR 7528 Mondes iraniens et indiens), Éditions de l'IFRI

Édition imprimée

Date de publication : 15 mai 2008

ISSN : 0240-8910

Référence électronique

Denise Aigle, «The Empire of the Qara Khitai in Eurasian History. Between China and Islamic World. Cambridge, Cambridge University Press, 2005, x-xxvi + 1-279 p. », Abstracta Iranica [En ligne], Volume 29 | 2008, document 150, mis en ligne le 15 septembre 2008, consulté le 26 septembre 2020. URL : http://journals.openedition.org/abstractairanica/27682 ; DOI : https://doi.org/10.4000/ abstractairanica. 27682

Ce document a été généré automatiquement le 26 septembre 2020.

Tous droits réservés 


\title{
The Empire of the Qara Khitai in Eurasian History. Between China and Islamic World. Cambridge, Cambridge University Press, 2005, $\mathrm{x}-$ xxvi + 1-279 p.
}

\author{
Denise Aigle
}

1 Le livre de M. Biran consacré aux Qara Khitai, ou Liao de l'Ouest, est un ouvrage majeur qui vient combler une lacune dans la connaissance de cette importante dynastie d'Asie centrale. Il s'agit de la première monographie en langue occidentale consacrée à cette dynastie d'origine mongole, les Kitan. Ces derniers avaient instauré leur pouvoir en Chine du Nord, sous le nom dynastique chinois de Liao. Dans l'introduction

2 (pp. 1-16), M.B. pose les problèmes méthodologiques auxquels se trouve confronté tout chercheur s'intéressant à ces empires d'origine nomade pour lesquelles les sources indigènes sont rares. En ce qui concerne les Qara Khitai, la seule source de ce type est le chapitre 30 du Liao shi (LS 30/355-8) qui retrace l'histoire politique et institutionnelle de la dynastie. Toutes les autres sources sont extérieures, souvent fragmentaires et contradictoires.

3 L'A. a divisé son livre en deux grandes parties : I. « Political History » (pp. 19-90) qui comporte trois chapitres relatant l'histoire politique complexe de l'empire des Qara Khitai ; II. « Aspects of cultural and institutional history » (pp. 93-201) qui constitue la partie la plus importante et novatrice de l'ouvrage. Cette seconde partie comporte elle aussi trois chapitres : « China » (pp. 93-131), « Nomads » (pp. 132-70) et « Islam » (pp. 171-201). Enfin suit une brève mais concise conclusion (pp. 202-11). L'ouvrage est complété par plusieurs annexes très utiles.

4 Je m'attarderai ici sur la seconde partie de l'ouvrage, dans laquelle l'A. inscrit la relativement courte histoire des Qara Khitai (circa 1131-1211, selon le Liao shi) dans le vaste cadre des empires nomades d'Asie centrale (du point de vue politique et culturel). 
M.B. montre, grâce à sa connaissance précise des sources en plusieurs langues, que dans l'empire des Qara Khitai, les institutions politiques, les pratiques administratives et les traditions culturelles comportaient de nombreux éléments chinois et islamiques. Elle explique que l'on trouve chez les Qara Khitai une innovation à propos du fonctionnement de l'armée : les soldats étaient payés et les commandants militaires ne recevaient pas de terres en apanage. Elle aborde ensuite les questions relatives à l'appartenance religieuse des sujets de l'empire qui était très diversifiée : bouddhistes, communautés chrétiennes nestoriennes, juifs, mais, surtout, les musulmans qui représentaient la plus grande part de la population de Transoxiane. L'A. parle de " tolérance religieuse " de la part des souverains Qara Khitai, ce qui me paraît être un peu en décalage. Dans ce cas et à cette époque, il serait plus approprié de parler " d'indifférence religieuse ». Dans cet empire, chaque communauté religieuse avait toute liberté pour pratiquer sa religion. À la question : « Pourquoi les Qara Khitai ne se sontils pas convertis à l'Islam ? »(pp. 190-201), l'A. suggère qu'ils ont résisté à l'islamisation en raison de leur fidélité aux traditions chinoises Liao. En effet, ils n'avaient pas besoin du soutien de leurs sujets musulmans, dès l'instant où ces derniers étaient libres de pratiquer leur culte en paix. Sur la question de la 'non conversion' des Qara Khitai, voir le c.r. de l'article du même auteur (c.r. $n^{\circ}$ 151). Pour conclure, M.B. écrit qu'il existe sans doute des similitudes entre les pratiques institutionnelles et administratives entre l'empire des Qara Khitai et celui des Mongols, mais elle insiste sur la spécificité propre des Qara Khitai. Cette étude restera longtemps le livre de référence sur une dynastie jusqu'ici demeurée peu connue, mis à part certains éléments de son histoire politique événementielle.

\section{INDEX}

Thèmes : 4.1. Histoire médiévale

\section{AUTEURS}

DENISE AIGLE

EPHE - Paris 